\title{
Sobre el Discurso de Parque Norte del Presidente Raúl Alfonsín del 1/12/1985 ${ }^{1}$
}

\author{
Mario Leandro Casás ${ }^{2}$ | Universidad Nacional de La Plata
}

Revista Derechos en Acción ISSN 2525-1678/ e-ISSN 2525-1686

Año 4/NN 11 Otoño 2019 (21 marzo a 21 junio), 629-639

DOl: https://doi.org/10.24215/25251678e292

Recuerdo que en mi adolescencia, con mis compañeros y como estudiantes del Colegio Nacional de San Nicolás de los Arroyos, mi pueblo, seguíamos con serena y apasionada expectativa y enfrentando a la realidad agresiva y desafiante de la época, a un conocido político, honesto y patriota, al que muchos de nosotros acompañamos hasta el fin de su vida.

De las tantas cosas que aprendimos de él, destaco una frase que no he podido olvidar y que decía: Un hombre, para no equivocarse, tiene que saber siempre donde se encuentra.

Hoy yo puedo repetir como él, que tengo la emoción de los que saben dónde están, porque hoy aquí, estoy como en mi propia casa, pero esta vez, honrado por una amigable invitación que me enaltece por su jerarquía, por la importancia del acontecimiento que provoca cual es la presentación del $\mathrm{N}^{\circ} 9$ de la que con toda modestia llaman REVISTA Derechos en Acción, y fundamentalmente, por la trascendencia de este querido Presidente Constitucional que estamos recordando, a través del que fue uno de sus mas culminantes mensajes.

Yo fuí a estudiar Veterinaria a La Plata, apenas terminé el bachillerato. Era común, en esas épocas, para la gente del interior del país, que se eligera esa ciudad ya que se consideraba a

\footnotetext{
Conferencia dictada en la presentación del Número 9 de ReDeA en la Facultad de Derecho de la Universidad de Buenos Aires.
}

2 Médico Veterinario. Doctor en Ciencias Veterinarias. Universidad Nacional de La Plata. 
Buenos Aires demasiado tumultuosa y con muchas tentaciones para los jóvenes inexpertos.

Trato ahora, por un instante, que mi vida recupere lo que ese tiempo ha borrado: esos horizontes ciertos sin cambios en la perspectiva y en el universo universitario de la Universidad de la Reforma Universitaria, manifiesto sublime que abrió la universidad, gratuita y laica, no solo a nuestro pueblo sino a todos los pueblos de América, recogiendo su sangre y su abolengo.

Y vengo, como digo, de los pagos de los Arroyos, del pueblo del acero y del agua bendita, de las glorias de Azopardo, de Pavón y de Cepeda, del Acuerdo de Urquiza después de su Pronunciamiento, de los matorrales llenos de belleza de sus Lechiguanas y de sus isleros en el Paraná de Obligado y donde sobraron los matreros, los facones, las tacuaras, las copas y guitarras, que hicieron las tinieblas del pueblo de Hormiga Negra, con sus sombras en sus zanjones orilleros, con sus ponchos, sus chambergos, sus tabas y barajas.

En San Nicolás a todos nos atraía mucho la historia y claro, pasábamos todos los días por la puerta del Museo de la Casa del Acuerdo al que visitamos tantas veces y veíamos sus objetos, sus cuadros y sus documentos y equitativo resulta que recuerde, reverentemente, ya que varios de Ustedes son constitucionalistas, que por esa vieja Casa pasó el santiagueño José Benjamín Gorostiaga, el de Chivilcoy, que fué amigo de don Leandro Alem y cuando el General Urquiza, junto al Vicepresidente Derqui, lo designó su Ministro del Interior, habiendo ocupado después otros honrosos cargos, en la República naciente.

$\mathrm{Y}$ al ver nada menos que en la tapa del $\mathrm{N}^{\circ} 9$ de la Revista que hoy presentan, el escudo de la Universidad en la que me gradué y a la que tanto le debo,con sus hojas de roble que nimban, en la Cruz del Sur, el espíritu de Rafael Hernández y del gran realizador y fundador Joaquín V. González, noto que mi vida hoy aquí recupera lo que ha borrado el tiempo, los rostros, las miradas, los lugares y el desconsuelo por mis queridos muertos escrito en dura piedra. 
Yo no acepté el ofrecimiento de ser Secretario General de esa Universidad. Un colega mío, que a su vez era amigo personal del Dictador que comandaba el llamado Proceso de Reorganización Nacional, había sido elegido Presidente de la Universidad Nacional de La Plata y pensó en mi, ese 1976, para acompañarlo.

A su vez me ofreció a que lo ayudase en la Presidencia del Consejo de Rectores de Universidades Nacionales, cargo que también ostentaba.

Él preveía mi negativa a raíz que conocía mi miitancia en un Partido Político pero pensó, quizá con razón, que yo tal vez podría facilitar el diálogo y la convivencia, en los oscuros tiempos que se avecinaban.

Este colega, ya fallecido, presidió la Universidad y el Consejo de Rectores, desde 1976 hasta el advenimiento de la democracia, en 1983.

Siempre quedó en mí, como un enigma, si mi injerencia desde la Secretaría General y desde el Consejo de Rectores hubiesen evitado, no solamente en La Plata, actos de intrigas, denuncias y delaciones que afectaron a los derechos humanos de la comunidad universitaria en esos oscuros años de terror y de plomo.

Igualmente es mi incógnita si mi actuación hubiera podido morigerar en algo tamaño desastre.

Por ello saludo con entrañable afecto a los distinguidos docentes platenses que nos acompañan.

Las circunstancias de mi ya larga vida me han hecho incursionar, tibiamente, en el periodismo.

Fui varios años, hasta su desaparición, Director de la Revista de Agronomía y de Veterinaria una publicación de López, Libreros-Editores, propietarios también de La Prensa Médica Argentina, en la calle Junín 845, frente a la Facultad de Medicina. Allí, desde 1914, se publicaba, en papel, esta revista científica tan importante para la medicina argentina. 
Asimismo editábamos Prensa Universitaria, en formato tabloid para lo cual contábamos con una rotativa formidable, que con bobinas, producía y doblaba, con gran velocidad, una enorme cantidad de ejemplares.

Una idea del querido editor, que también era mía, era producir un diario de distribución gratuita, llamado La Prensa Agraria Argentina, con alcance nacional, y desde donde ibamos a difundir ideas progresistas, acerca de la reforma agraria inmediata y profunda que sosteníamos en esas épocas, fundamentos del cooperativismo y otras formas de asociativismo agrario, como así también progresos en la prevención de enfermedades de los animales, nuevos métodos de labranza, la adaptación de los nuevos híbridos en la naciente avicultura industrial de ese tiempo, sus contratos de integración vertical también para nuestros tambos y los productores de alimentos balanceados y tantos proyectos e ideas para el lanzamiento.

Pero un día, un triste día, de principios del ya convulsionado 1975 nos colocaron una bomba en la imprenta y el editor y su familia debieron irse del país.

Con él se fue el plan y su intención. Nunca más pude resucitarlo y la máquina soñada, esa rotativa hechizante y mágica, fue desarmada y vendida.

Por eso, por mi frustrada experiencia en estas artes, al ver hoy esta presentación de lo que tan humildemente llaman Revista, me permito rectificarlos y señalarles que por su contenido y la diversidad de sus temas que también incluyen a la actividad agraria, por su nivel y por su cuidado gráfico, imás que una revista, este número $9^{\circ}$ de Derechos en Acción, es un Libro de Cabecera!.

Cuando me brindaron el privilegio de invitarme a esta presentación de este Noveno Número de Derechos en Acción, y que debía hacerlo ante tantos abogados prestigiosos, me vino a la memoria cuando yo era estudiante en tiempos que presidía la Universidad Nacional de La Plata el Profesor José Peco, el célebre autor del Tratado acerca de la Reforma del Código Penal 
Argentino. El brillante Decano de mi Facultad, a su vez Vicepresidente del Consejo Superior, Profesor Constantino Brandariz, improvisadamente lo llevó a conocer las instalaciones de la Casa de Estudios y le pidió que nos dijera unas palabras.

Con la humildad de los grandes el Dr. Peco, que fue Decano de esta facultad de Derecho, que había sido Diputado de la Nación y falleció siendo nuestro Embajador en Austria, designado por el Presidente Illia, se preguntó, en voz alta, que podía decirnos un abogado a nosotros, futuros veterinarios, referido a la actividad en la que habríamos de desempeñarnos en el futuro.

Trajo entonces, con la capacidad de un maestro, la figura de un jurista español que estudió en Oviedo, polifacético autor del Delincuente honrado, gran amigo del pintor Francisco de Goya y creador, en 1804, de la Introducción de la Ley Agraria en el Principado de Asturias.

Nos contó el Dr. Peco cosas que aún recuerdo no obstante que ha pasado más de medio siglo de lo que les relato: que Jovellanos creó la Escuela de Mineralogía y Náutica en Guijón,uno de los más antiguos centros educativos de enseñanza media en España-; que fué Embajador del Reino de España en Rusia, destacadísimo cargo para la época además que, quizá lo más importante, llegó a desempeñarse en El Escorial, durante solo nueve meses, como Ministro de Gracia y Justicia del Rey Carlos IV, enfrentando al intrigante Primer Ministro Manuel de Godoy.

Jovellanos reformó nada menos que el Sacro Tribunal de la Inquisición, el de los monjes ociosos, como los calificó el Dr. Peco en aquella conferencia inolvidable.

El Rey Carlos IV registra, entre los logros de la época (a consecuencia de Jovellanos) el fomento de la Agricultura. Nadie, antes que Jovellanos, vio que el porvenir de España residía en la riqueza de sus campos bien labrados.

Salvando el tiempo y la distancia y, sobretodo, la capacidad y estatura intelectual del Dr. José Peco de la que a todas luces carezco, me toca hoy a mi preguntarme ¿Qué puede transmitir a Ustedes, señores abogados, este antiguo Centauro, este oscuro 
y por ahí veterinario rural y de los frigoríficos y que, ya viejo y sin fuerza para nada, hoy ya tiene los ojos chiquitos de tanto mirar al sol y a la noche oscura?.

Decirles simplemente que, hace treinticinco años, en una cálida tarde de febrero, me llamó telefónicamente Richard Pueyrredón, buen amigo y Director Nacional de Ceremonial, para decirme que el Presidente Alfonsín quería hablar conmigo y que podía recibirme de inmediato.

Yo integraba, en ese tiempo, la Convención del Partido Gobernante.

A principios de 1984 ser llamado por indicación del Dr. Alfonsín para una entrevista directa con él, era fascinante para cualquier ciudadano ya que el momento provocaba una atracción tan favorable en todos nosotros que, inusitadamente, aceptábamos el compromiso, -casi una obligación-, como si nos convocara un talismán para una conjura.

Y así fue realmente y me pidió que lo acompañara en su Gobierno, ayudando a conducir el Instituto Nacional de Tecnología Agropecuaria, más conocido como INTA.

Y allí estuve hasta que volví a la Casa Rosada y le dejé mi renuncia en sus manos,-estaba acompañado por el Vicepresidente Martínez-, los primeros días de julio de 1989.

La entrevista que tuve a solas con el nóvel Presidente fue para mi inolvidable ya que noté de inmediato que conocía intensamente al INTA, organización que me era muy familiar por mi anteriores actividades en un laboratorio extranjero, que producía antibióticos para uso veterinario y un herbicida con altísima penetración en el mercado de la soja.

El Presidente tenía un claro proyecto de impulsarlo, basándose en un trípode que era la descentralización operativa, la integración y la participación en el manejo del Instituto.

Sostuvo que si yo aceptaba el cargo que me estaba ofreciendo, era para llevar a cabo esos movimientos y tratando de conseguir que el Instituto, con sus cinco mil empleados, propusiera una clara y definida Política Agropecuaria Nacional, contemplando, 
entre otros paradigmas, a los recursos sustentables y a las economías regionales, para conseguir un Estado eficiente y con una riqueza sectorial articulada y altamente competitiva.

Señaló que el INTA no podía seguirse manejando desde Buenos Aires y era menester descentralizarlo, integrándolo en regiones haciendo participar a los productores y sus asociaciones, a los técnicos locales, a las Universidades de cada región y a la comunidad científica.

Pero para ello resultaba imprescindible dotarlo de recursos económicos para lo cual iba a elevar un proyecto de Ley al Congreso Nacional a fin que se sancionara que debían ingresar al INTA el uno y medio por ciento del valor del total de las exportaciones agropecuarias, el que sería administrado en forma autártica bajo el control del entonces Tribunal de Cuentas de la Nación.

Fácilmente imaginarán que, ante tal exposición, era imposible negarme a acompañar a todo un estadista.

En ese momento se me había ofrecido también, ser director operativo de un importantísimo laboratorio norteamericano radicado en Buenos Aires pero, coincidentemente, tenía a mis dos únicos hijos en plena adolescencia. Ambos, que cursaban el bachillerato en la escuela pública, simpatizaban con el nuevo gobierno y estaban entusiasmados con la vuelta a la democracia, que no habían conocido.

Vino entonces a mi memoria una película que yo había visto hacía tiempo y que se llamaba ¿Qué biciste vos en la guerra, papá?, una comedia bélica desarrollada en Sicilia con James Coburn y música de Henry Mancini.

El temor que alguna vez mis hijos me enrostraran esa frase, era tremendo para mí y tomé la decisión que no fue fácil ya que la diferencia económica entre ambas asignaciones era abismal.

Nunca he vuelta a tocar ese tema con ellos, que ya tienen más de cincuenta años y han constituidos sus familias brindándome cinco nietos increíbles. 
La atracción que ejercía el Presidente en ese momento y que pude comprobar en los viajes en que tuve el honor de acompañarlo, era sorprendente.

Sus respuestas, su espontaneidad, su simpatía, su sencillez, pero a la vez su energía, daban la impresión que colocaba piedra sobre piedra como un maestro artífice de la hermosura, de lo elegido, de lo selecto, de lo ecléctico.

En este caso el gallego se transformaba en un florentino renacentista armando sus frisos y sus cúpulas, sus frontispicios fastuosos y sus mansardas elegantes que atisban el infinito.

Yo cumplí mi trabajo, usé todas las habilidades que creí tener, escuché con atención a los que sabían y empleé todos los medios lícitos para conseguir los objetivos propuestos por el Presidente.

Los importantísimos recursos con que se dotó al INTA permitieron construir laboratorios, rearmar las Estaciones Experimentales, reequipar la flota, becar a 330 jóvenes técnicos con sus familias algunos de los cuales estuvieron especializándose en destacados centros científicos de Europa y de Estados Unidos, previa firma de un contrato que, a su regreso, los comprometía a permanecer en el Instituto durante un mínimo de cinco años.

Firmamos un convenio con el Banco Interamericano de Desarrollo y el Banco de la Nación y ejecutamos la confección del Mapa de Suelos por el cual se ha evaluado cada hectárea de nuestro territorio a fin de poder recomendar, a cada productor agropecuario, cual es la mejor explotación que se adapta al mismo.

Visité a casi todos los gobernadores, me hice amigo de muchos de sus Ministros de Agricultura, me nombraron Secretario del Consejo Federal Agropecuario, descentralizamos al INTA y mal que le pesara a algún unitario que siempre queda, los Consejos Regionales manejaron su propio presupuesto y produjeron la recomendación de cuál era la tecnología que había que aplicar en cada zona del país.

En los primeros años del Gobierno me tocó vivir, una vez con el Ministro Conrado Storani en una cena en un importante Hotel de esta Ciudad en donde debimos reaccionar con cierta 
violencia en nuestras palabras, y otras en algunas de las exposiciones rurales del interior, ciertas indirectas y resquemores referidos a la necesidad real y oportunidad de haber enjuiciado a los integrantes de las Juntas Militares.

El clima que notábamos a partir de abril de 1985 después que la Justicia comenzó a ejecutar el Decreto No 158/83 dictado por Presidente a cinco días de haber asumido e iniciando los juicios, era enrarecido en algunos sectores.

Los que veíamos con frecuencia al Dr. Alfonsín estábamos preocupados por su seguridad y cualquier actitud nos alertaba y nos traía el desasosiego que algo desagradable podía ocurrirle.

Así en una oportunidad, me tocó atender y acompañar, en su nombre y a lugares que su tiempo no se lo permitía, la Visita de Estado del primer Presidente de la República de Cabo Verde, Arístides María Pereira, un socialista que había bregado por la independencia de ese país africano y que también hizo lo propio con la independencia de Guinea.

El Presidente me explicó que era un luchador de mucha ascendencia ante países tan pobres que bregaban por su libertad, los que le tenían un gran respeto y dada la proximidad de una elección clave en la Causa de Malvinas cuyo voto favorable ya había adelantado, era oportuno que le transmitiéramos el reconocimiento del Gobierno.

Con tal motivo acompañé al Presidente a recibirlo en el Sector Militar del Aeroparque. Me ubicaron detrás de él y el Canciller junto al Edecán y al que sería mi acompañante en las jornadas siguientes, el después embajador Abel Posse, un integrante de nuestro Servicio Exterior.

Cuando se produjo el arribo, antes que la fanfarria iniciara las interpretaciones de los himnos, se dispararon los veintiún tradicionales cañonazos.

El detonante desprendió mucho humo y el Presidente se dio vuelta y le dijo al Edecán en tono enérgico:"Le pusieron mucha pólvora a las cargas" recibiendo, de su parte, un lacónico:"Si señor Presidente". 
Rápidamente interpreté que el hecho no revestía casualidad sino que era una de las tantas "travesuras" que le tendían con frecuencia, quizá desafiando quien tenía el poder. Al comentarlo con otros funcionarios, todos vimos la mala intención en la circunstancia vivida.

Un año después el Presidente me designó para atender a otro visitante ilustre: el Presidente de la también africana República de Mozambique, Joaquín Alberto Chissano, en Visita de Estado, y la ceremonia de recepción fue idéntica pero los cañones atronaron sin lanzar tanto humo.

Los Comandantes ya habían sido condenados.

Yo, por supuesto, estuve en Parque Norte ese domingo $1^{\circ} \mathrm{de}$ diciembre de 1985 y sentí la vibración espiritual que provocó, en todos los presentes, la Convocatoria para una Convergencia Democrática expuesta por Presidente ante los integrantes del, -en ese momento casi centenario Partido-, donde los valores de modernización se entrelazan con los éticos.

Lo que acabo de transmitirles y que me dijo cuando me ofreció ser un funcionario de segundo o tercer nivel de su flamante Gobierno, son las mismas ideas-fuerza que constituyen la ecuación con las incógnitas que nos transmitió en esa oportunidad en Parque Norte y que Ustedes hidalgamente han recogido en la Revista: integrar, modernizar, participar, descentralizar, abrir el juego, agrandar los espacios de libertad, de bienestar y de relación humana consiguiendo que cada argentino posea el poder de opinión, el poder de decisión y el poder de construcción, convirtiéndose en el Sujeto Democrático, el de la legitimidad del disenso, aceptando las reglas básicas de la convivencia social, del respeto a las diferencias y del pluralismo.

Este elocuente discurso del Presidente Alfonsín le puso color al pensamiento y consiguió asirlo, asediarlo y, lo que es más importante: transmitirlo. Un Presidente en serio, clarividente y rico de humilde paz, modesto, sin soberbia. Un maestro que hace enorgullecer a quienes fuimos sus colaboradores. Un luchador formador de juventudes. 
$\mathrm{Al}$ igual que el Presidente Yrigoyen desarrolla, en el mismo, la concepción pluralista del Estado y la doctrina de eticidad del derecho que han de renovar los planteamientos federalistas y las definiciones morales de la democracia argentina tras los destinos perseguidos......

...Porque si algún día hubiesen muerto/ los destinos perseguidos / los fogones extinguidos y los potreros desiertos / los batallones inciertos de los gauchos que se han ido ;Van a volver del olvido, para tenernos despiertos! 